\title{
The Quality of Health Records used in the Processing of Lawsuit Cases,
} A Study in Zabol, Iran

\author{
Research Article
}

\section{Abbas Sheikhtaheri ${ }^{1}$, Ali Aliabadi ${ }^{* *}$, Samaneh Saravani Aval $^{3}$}

1. Assistant Professor, Department of Health Information Management,

School of Health Management and Information Sciences, Iran University of Medical Sciences, Tehran, Iran

2. PhD student of Health Information Management, Department of Health Information Management, School of Health Management and Information Sciences, Iran University of Medical Sciences, Tehran, Iran

3. Instructor of Health Information Technology, Department of Health Information Technology, School of Allied, Zabol University of Medical Sciences, Zabol, Iran

\begin{abstract}
Background: Forensics is one of the most important areas for the use of health records. Annually, thousands of people refer to forensic medicine organizations to receive health records relating to assaults, accidents, conflicts, medical malpractice, examining the corpse, and clinical examinations. The purpose of this study was to analyze the quality of health records that were used in Zabol Department of Forensic Medicine. Method: In this descriptive cross-sectional study, five hundred health records in total were examined. Data were extracted from health records archived in the Department of Forensic Medicine. Data was collected using a checklist. Data were analyzed by SPSS18 software program. Results: The results showed that $71.2 \%$ of the lawsuits were associated with accidents. As for ineffectiveness of the health records, 415 cases $(83 \%)$ and 441 cases $(88.2 \%)$ were associated with inaccuracies and incompletely collected information, while 149 cases $(29.8 \%)$ were associated with the lack of signature and sealing. Conclusion: The quality of the health records under study was not acceptable and despite the importance of legally correct documentation, information was defective. Medical records' documentation has numerous weak points in terms of accuracy, completeness, consistency, and being signed and sealed.
\end{abstract}

Keywords: Forensic Medicine, Health Records Quality, Documentation.

\section{Background}

Health information is considered the greatest capital of health care organizations and the importance of health records as the main source of health information in the areas of patient care, quality improvement, financial reimbursement, law enforcement, education, research and planning is not a secret (1). Health records consist of health information about treatment measures of patients, and patients may use their records to continue their treatments in hospitals and other centers and to claim their rights in judicial and administrative organizations (2). Health records are valuable tools in providing high quality patient care, disease prevention and health promotion (3).

As noted before, one of the most valuable aspects of health records is regarding legal issues (4). Health records are mostly applied in the legal aspects of forensics, judicial inquiries, and pursuit of ill-treatment caused by medical negligence (1). Judicial authorities can effectively deal with the complaints and claims

*Corresponding Author:

\section{Ali Aliabadi}

PhD Student,

Department of Health Information Management,

School of Health Management and Information

Sciences, Iran University of Medical Sciences,

Tehran, Iran

Email: aliabadi.a@gmail.com made by a patient or his/her close relatives based on high quality health records (5). Judgment is a very complex and sensitive affair that is associated with all aspects of life and work life. In most medical cases, the judges' decisions are dependent on forensics' opinions, and their comments are based on the documentation and information recorded in health records (6). Judges, by the study of the facts documented in a patient's health record, can verify or reject negligence (7). Health records may defend the rights of patients, medical staff, and hospitals and can lead to the immunity of hospitals from patients' lawsuits (8); therefore, the presence of adequate information to respond to forensics referrals is very important (9). The content of health records must be perfect to justify the performed diagnoses and treatments (7).

In legal cases, a health record with low quality information can be considered an indication for imperfect care and treatment (10). Quality of health information is often expressed based on its relevance, completeness, accessibility, timeliness, accuracy, and readability (3). The results of a study by Jedi et al. showed that more than $50 \%$ of health records were used in legal cases, most of which were related to specialized surgeries and emergency care (11). In this context, the study of Shakibaei showed that the majority of requests for health records $(73 \%)$ were associated with the judicial authorities (12). Now, given the large volume of lawsuit cases in departments of forensic medicine, and the need to respond to them, it is necessary to study the 
quality of the information sources to meet these needs. Therefore, this study was conducted to analyze the quality of health records requested by Zabol Department of Forensic Medicine in the processing of lawsuit and complaint cases.

\section{Materials and methods}

This descriptive study was conducted retrospectively. For this study, an introduction letter was presented to the authorities of forensic medicine organization for collecting information and their agreement was obtained and an informed consent letter was taken from the studied units and they are assured that their information would be held confidential and the results would be used merely in research activities. Five hundred health records requested by the forensic medicine organization were randomly selected and investigated. We investigated the type of documents requested, reasons of complaints and lawsuits, reasons for non-use of health records, and the reasons for the request of health records. To collect data, a two-part checklist was developed. The first part included patients' demographic data and the second part was related to the questions based on the research objectives. The content validity of the checklist was confirmed by the judgment of a panel of 10 experts.

Data was collected in the Forensic Medicine Organization through reviewing the records and existing documents. It should be noted that in order to analyze the reasons for the non-use of health records, a forensic medicine expert and a health information expert evaluated the documentation principles. Finally, SPSS 18 software was used to analyze the data.

\section{Results}

Among the lawsuits, $84 \%$ were related to male patients; the mean age of the patients was $28.05 \pm 15.73$ years.

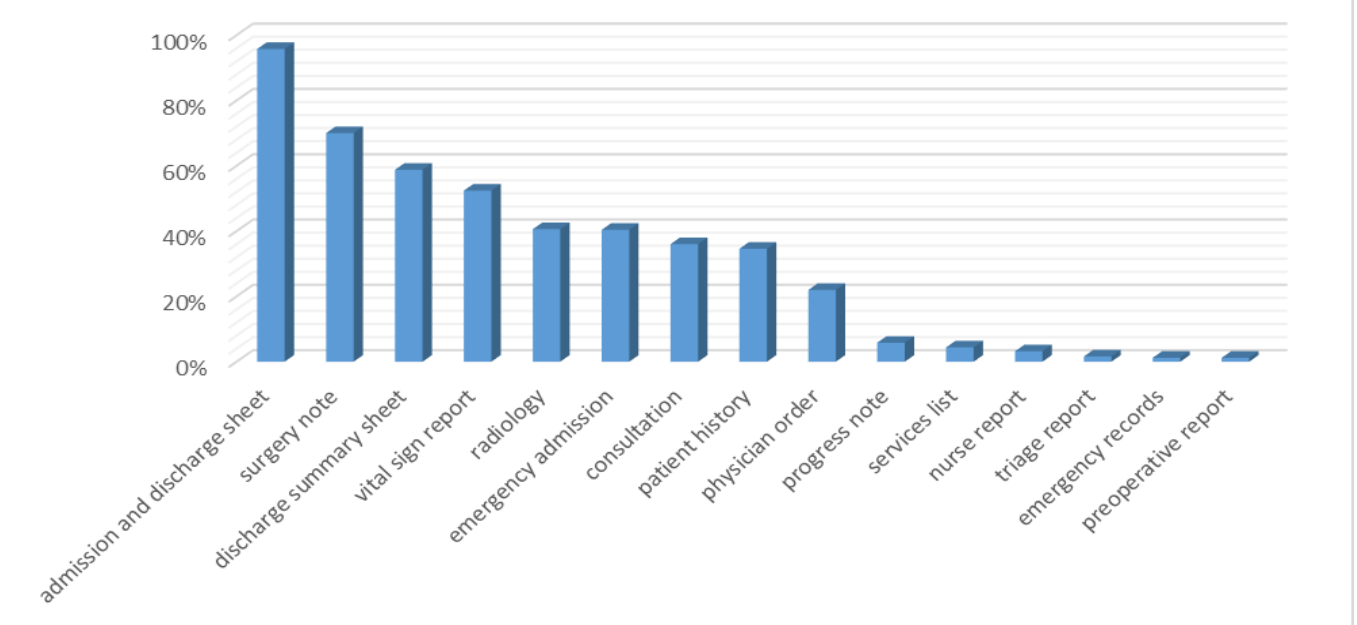

Figure 1: Distribution of documents requested by Zabol Department of Forensic Medicine.

In cases of the requested health information, admission and discharge reports $(95.8 \%)$, surgery notes $(70 \%)$, discharge summary sheets $(58.8 \%)$ and vital sign reports $(52.4 \%)$ were the most frequently requested documents, as is shown in Fig. 1.

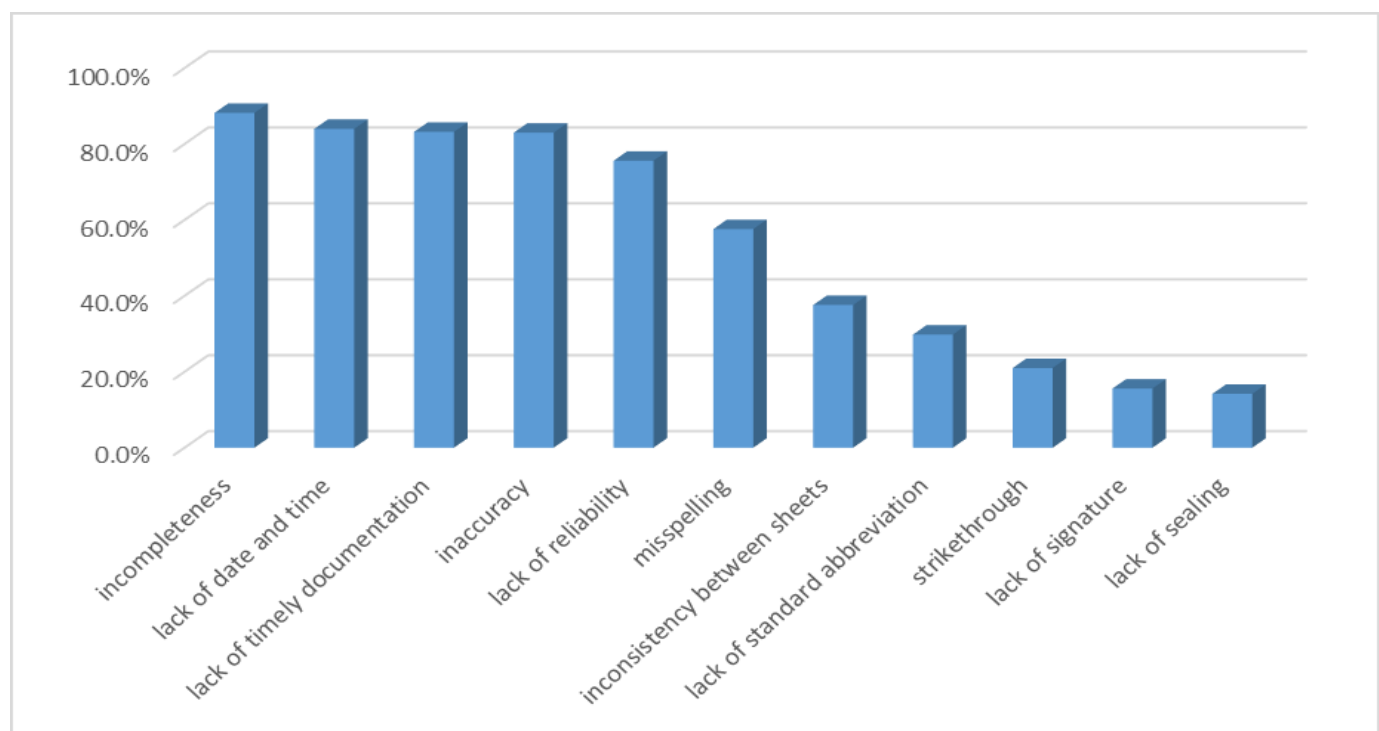

Figure 2: Distribution of the causes of non-use of health records based on the principles of documentation. 
Based on the results, the most frequent reasons for non-use of the health records (rejection of records by the department) were incompleteness $(88.2 \%)$ and lack of date and time (84\%). (Fig. 2)

Among the total 500 cases of referrals to Zabol Department of Forensic Medicine, most referrals related to accidents $(71.2 \%)$ and conflicts $(22.4 \%)$. The lowest percentage of the referrals belonged to accidents at work $(1.6 \%)$, while other cases (psychiatric, death due to labor, blood disease, suicide, gastric cancer) were $4.8 \%$.

The results indicated that the most frequent reasons for referrals were associated with preliminary examinations $(91.6 \%)$ and with determining the amount of blood money (62.6\%). The next referral reasons, being consulting and forensic examination and examining the corpse after natural death, were $57.2 \%$ and $10.6 \%$, respectively, and the lowest percentage of referral reasons, belonging to other reasons (mental health, physical health, and issuing of a death certificate), was $4.4 \%$.

\section{Discussion and conclusion}

Health records are important resources to support the legal rights of patients, physicians, and health care institutions (13). People who record the contents of health records have a huge impact on the quality of these records. All people who document patient information should fully understand the importance of creating an accurate and complete record and its legal issues (4). The awareness by health care providers of the fulfillment of the laws governing health records and health information of patients should provide conditions to realize patient rights (9). Seidel wrote to the physicians, "remember that the patient's health record is a legal document and any information may be used in the courts" (14).

This study showed that the quality of health records is not acceptable for legal affairs, and defective documentation and incomplete records $(88.2 \%)$ were the main reasons for the ineffectiveness of the records referred to forensic medicine organizations. This was consistent with the results of the study by Farzandipour (6).

The results of a study by Rabiee et al. on the assessment of the quality of data recorded in the health records in teaching hospitals of Tehran showed that health records suffered serious defects in terms of recorded data and in terms of lack of observing proper documentation. The assessment also showed lack of responsibility of students and interns for proper principles of documentation and lack of necessary training for clinicians about principles of documentation (15). The study of $\mathrm{Pau}$ et al. in analyzing the documentation of the drug reaction of patients showed that $20 \%$ of cases of drug reactions were not recorded. This study showed that non-recorded cases were not due to the patients' inability to mention them but were due to the medical negligence in obtaining the full descriptions from the patients (16).

One of the major causes of defective health records is the lack of knowledge of physicians and medical staff regarding the principles of documentation and the legal aspects of health records (15). In this context, Farzandipour's study showed that most physicians, residents, and medical students lack sufficient training to complete records (6). The study by Sheikhtaheri to analyze the knowledge of physicians, nurses, and health records staff on the legal aspects of health records in teaching hospitals showed a moderate level of knowledge (4). Similarly, the study conducted by Ahmadi et al. showed that the health providers' awareness about legal aspects of health records was moderate (9).

In spite of our results, Safdari indicated that the quality of health records referred to forensic medicine organizations was relatively favorable. The main reason stated by Safdari was resolving the deficiencies in the records. Referring to the fact that a significant portion of the health records sent from health care organizations lacked the necessary documentation (7), and that training staff in the field of documentation is necessary, other Iranian studies emphasized the importance of the quality of health records in this regard (17).

Given that correct documentation makes the health records a primary tool for performance evaluation and plays an important role in forensic investigations, hospitals should attempt to identify factors influencing the quality of documentation of health records to improve health records in forensic investigations. Evaluation of the accuracy, completeness, and readability of health records not only increases the use of health records, but also increases the reliability and validity of studies conducted based on this information. Therefore, the use of new information systems to access data and the faster processing of data, better documentation and adopting methods to improve quality, are essential for better use of health data.

In addition, the need to set up workshops and training courses for better familiarity of the care providers with the principles of documentation and legal aspects of health information is proposed.

\section{Acknowledgements}

The authors thank the Student Scientific Research Center in Zabol University of Medical Sciences for financially supporting this study.

\section{References}

1. Ahmadzadeh F, Ahmadzadeh G, Hospital administrators and medical staff viewpoint about medical record application in Shiraz University of Medical Records. HIM J. 2005; 4(2);27-32.

2. Rathor M.Y, Rani A, Fauzi M, How S.H, Rasool A.G, Rehana K, Awareness, knowledge and attitude towards informed consent among doctors in two different cultures in Asia: a cross-sectional comparative study in Malaysia and Kashmir, India. Singapore Med J. 2007; 48(6); 559-565.

3. Karami M, Shokrizadeh Arani L, Related Factors in Medical Records Documentation Quality and Presenting Solutions from Managers' and Physicians' Viewpoints Occupied in Hospitals Affiliated to Kashan University of Medical Sciences. Iran J Med Educ. 2010; 9 (4);356-364 
4. Sheikhtaheri A, Kimiafar Kh, Barati Marnani A. Knowledge of Physicians, Nurses and Medical Record Personnel about Legal Aspects of Medical Records in Teaching Hospitals Affiliated to Kashan University of Medical Sciences. Health Information Management 2010 ;7(2): 146-152.

5. Saliba V, Legido-Quigley H, Hallik R, Aaviksoo A, Car J, McKee M, Telemedicine across borders: a systematic review of factors that hinder or support implementation. Int J Med Inform. 2012;81(12);793 $-809$.

6. Farzandipoor M, Shokrizade L, Meidani Z, Rangrazjedi F, The Response rate of cases Referred to the medical Records of Forensic Medicine Kashan. Proceeding of the second international congress of forensic medicine, iran 2011; 135.

7. Safdari R, Khodabande F, Abolmasoomi Z, Ghazisaeedi M, Sharifian R, Masoori N, Akbarzade $\mathrm{R}$, The Study of Accountability Rate of Medical Records in Referral Cases to Forensic Medicine. Journal of Forensic Medicine2012; 17(1): 29-36.

8. Sadrodini F, Medical record from the viewpoint of legal medicine. Journal of Legal Medicine. 1998; 4 (13); 85-90. [in Persian]

9. Ahmadi M.S, Sheikhtaheri A, Kimiafar K, Esmaeili M, Mosavi M. Knowledge of health care providers about legal aspects of medical records in teaching hospitals affiliated to Lorestan university of medical sciences. Yafte, 2011; 13 (3);45-55

10. Siamian H, Aligonbadi K, Nasiri, E, Shahrabi A, The role of health information management in hospital management. Monthly Scientific Communication. 2005; 4(3);102-112.
11. Rangraz Jedi F, Farzandi Pour M, Mousavi S.G, Utility of medical sciences content in hospitals of Kashan towns in 2003. Health Inf Manage. 2007;8 (1); 88-94.

12. Shakibaei S. Review of medical records in hospitals of Shiraz in data exchange.The First Congress of Medical records; 19-21 October Iran Shiraz University of Medical Sciences 2003; 113-118.

13. McAllum C, St George, I, White G, Death certification and doctors' dilemmas: a qualitative study of GPs' perspectives. Br J Gen Pract. 2005; 55(518); 677-683.

14. Seidel H.M, Stewart R.W, Ball J.W, Dains J.E, Flynn J.A, Solomon B.S. Mosby's guide to physical examination.11ed. Elsevier Health Sciences;2010.95p.

15. Seif Rabiee M.A, Sedighi I, Mazdeh M, Dadras F, Shokouhee Solgi M, Moradi A, Study of Hospital Records Registration in Teaching Hospitals of Hamadan University of Medical Sciences in 2009. Sci J Hamadan Univ Med Sci. 2009; 16 (2);45-49.

16. Pau A.K, Morgan J.E, Terlingo A, Drug allergy documentation by physicians, nurses, and medical students. Am J Health Syst Pharm. 1989; 46(3);570 -573 .

17. Farzandipour M, Sheikhtaheri A, Evaluation of factors influencing accuracy of principal procedure coding based on ICD-9-CM: An Iranian study. Perspect Health Inf_Manag. 2009;6(5). 